\title{
Ticagrelor Versus Prasugrel for the Treatment of Patients with Type 2 Diabetes Mellitus Following Percutaneous Coronary Intervention: A Systematic Review and Meta-Analysis
}

Hua Yang $\cdot$ Bing Tang $\cdot$ Chen Hong Xu $\cdot$ Anis Ahmed

Received: October 23, 2018 / Published online: November 19, 2018

(C) The Author(s) 2018

\begin{abstract}
Introduction: Antiplatelet therapy is very important following percutaneous coronary intervention (PCI). New generation $\mathrm{P}^{2} \mathrm{Y}_{12}$ inhibitors (ticagrelor and prasugrel) might potentially replace clopidogrel for the treatment of post-interventional acute coronary syndrome (ACS). In this analysis, we aimed to systematically compare the post-interventional clinical outcomes and bleeding events observed with ticagrelor versus prasugrel in patients with type 2 diabetes mellitus (T2DM).

Methods: EMBASE, MEDLINE, the Cochrane Central Register of Controlled Trials, and www. ClinicalTrials.gov were carefully searched for publications comparing the post-coronary interventional outcomes following ticagrelor versus prasugrel use in patients with T2DM. Adverse clinical outcomes and bleeding events were considered as the endpoints. Statistical
\end{abstract}

Enhanced Digital Features To view enhanced digital features for this article go to https://doi.org/10.6084/ m9.figshare.7314689.

H. Yang $(\varangle) \cdot$ B. Tang · C. H. Xu

Department of Cardiology, Jingzhou Central

Hospital, The Second Clinical Medical College,

Yangtze University, Jingzhou 434020, Hubei, China

e-mail: 18107168135@163.com

A. Ahmed

Department of Internal Medicine, Ealing Hospital,

University of Buckingham, London, UK analysis was carried out by the Revman software (version 5.3). Odds ratios (OR) and 95\% confidence intervals $(\mathrm{CI})$ were used to represent the data during subgroup analysis.

Results: A total of 2004 participants with T2DM were included in this analysis. Following PCI, mortality (OR 1.00, 95\% CI 0.57-1.76; $\left.P=0.99, I^{2}=19 \%\right)$, myocardial infarction $(\mathrm{OR}$ $0.86,95 \%$ CI $0.42-1.75 ; \quad P=0.67, I^{2}=0 \%$ ), major adverse cardiac events (OR $0.73,95 \%$ CI $0.42-1.27 ; P=0.27, I^{2}=0 \%$ ), and stroke (OR $0.72,95 \%$ CI $0.20-2.59 ; P=0.61, I^{2}=0 \%$ ) were not significantly different between ticagrelor and prasugrel. In addition, total bleeding events (OR 0.87, 95\% CI 0.55-1.40; $P=0.58, I^{2}=6 \%$ ), Thrombolysis in Myocardial Infarction (TIMI) defined minor bleeding (OR 2.39, 95\% CI 0.58-9.91; $\left.\quad P=0.23, \quad I^{2}=0 \%\right), \quad$ TIMI defined major bleeding (OR 1.42, 95\% CI 0.27-7.45; $P=0.68, I^{2}=0 \%$ ), bleeding defined according to the Bleeding Academic Research Consortium (BARC) major bleeding (OR 0.55, 95\% CI $\left.0.22-1.36 ; \quad P=0.20, \quad I^{2}=0 \%\right), \quad$ BARC minor bleeding (OR 1.44, 95\% CI 0.52-3.99; $P=0.48$, $I^{2}=0 \%$ ), and total minimal bleeding (OR 3.12, 95\% CI $0.55-17.59 ; P=0.20, I^{2}=0 \%$ ) were also not significantly different.

Conclusion: Ticagrelor and prasugrel were not associated with significantly different adverse clinical outcomes and bleeding events in these patients with T2DM. Therefore, both antiplatelet agents might safely be used in patients with T2DM following coronary intervention. 
However, this head-to-head comparison still remains a major challenge which should be resolved in larger clinical trials.

Keywords: Bleeding events; Clinical outcomes; Percutaneous coronary intervention; Prasugrel; Ticagrelor; Type 2 diabetes mellitus

$\begin{array}{ll}\text { Abbreviations } \\ \text { CVD } & \text { Cardiovascular disease } \\ \text { CAD } & \text { Coronary artery disease } \\ \text { PCI } & \text { Percutaneous coronary intervention } \\ \text { T2DM } & \text { Type } 2 \text { diabetes mellitus }\end{array}$

\section{INTRODUCTION}

Antiplatelet therapy is very important following percutaneous coronary intervention (PCI) to reduce the risk of post-interventional complications. However, bleeding risk might be a limiting factor of these blood thinners [1]. New generation $\mathrm{P}_{2} \mathrm{Y}_{12}$ inhibitors (ticagrelor and prasugrel) might soon replace clopidogrel for the post-interventional treatment of patients with acute coronary syndrome (ACS) [2]. This was indicated in the Trial to Assess Improvement in Therapeutic Outcomes by Optimizing Platelet Inhibition with Prasugrel-Thrombolysis in Myocardial Infarction (TRITON-TIMI 38) and the PLATelet inhibition and patient Outcomes (PLATO) trials [3, 4].

The newer antiplatelet agents ticagrelor and prasugrel have faster and stronger platelet inhibition in comparison to the commonly used clopidogrel [5] following coronary angioplasty and hence the European guidelines now recommend both antiplatelet drugs as first-line choice for the post-interventional treatment of patients with ACS [6].

Recently, a few meta-analyses based on the general population comparing the efficacy and safety of ticagrelor versus prasugrel were published. However, controversial issues were observed. For example, a head-to-head comparison by Bundhun et al. showed comparable outcomes between ticagrelor and prasugrel for the treatment of patients with ACS [7]. Bleeding events were also similarly observed.
Nevertheless, another head-to-head comparison by Sakurai et al. showed prasugrel to be associated with lower risk of bleeding events in comparison to ticagrelor [8].

Patients with type 2 diabetes mellitus (T2DM) are at higher risk of thrombosis due to platelet dysfunctions [9]. Clopidogrel hyporesponsiveness was also observed in this subgroup of patients following PCI [10]. However, those newer potent antiplatelet agents were not systematically compared in a subgroup of patients with T2DM.

In this analysis, we aimed to systematically compare the post-interventional clinical outcomes and bleeding events observed with ticagrelor versus prasugrel in patients with T2DM.

\section{METHODS}

\section{Search Strategies (Data Sources, Search Terms, Inclusion and Exclusion Criteria)}

The database of EMBASE (www.sciencedirect. com), MEDLINE including its subset PubMed, the Cochrane Central Register of Controlled Trials, and www.ClinicalTrials.gov were carefully searched for publications comparing the postcoronary interventional outcomes following ticagrelor versus prasugrel use in patients with T2DM. Articles which were published in English were considered relevant to this analysis.

"Ticagrelor, prasugrel and percutaneous coronary intervention", "ticagrelor, prasugrel, percutaneous coronary intervention and diabetes mellitus", "ticagrelor, prasugrel, diabetes mellitus", "ticagrelor, prasugrel, coronary artery diseases", "prasugrel, ticagrelor, acute coronary syndrome", "ticagrelor, prasugrel, coronary angioplasty", "prasugrel, ticagrelor, myocardial infarction" were the search terms which were used.

The inclusion criteria were:

(a) Randomized or non-randomized trials comparing the post-interventional clinical outcomes and bleeding events in T2DM patients following treatment with ticagrelor versus prasugrel

(b) Studies which involved data that could be used to carry out this analysis 
The exclusion criteria were:
(a) Meta-analyses, literature reviews, and let- ters to editors
(b) Studies which did not report the corre- sponding endpoints
(c) Studies only reporting platelet aggregation without considering the post-interven- tional endpoints or bleeding events
(d) Studies that included data which could not be used in the analysis
(e) Duplicated studies

\section{Types of Participants and Outcomes Reported}

All the participants were T2DM patients with coronary artery disease of different degree (ST and non-ST segment elevated myocardial infarction, ACS) who recently underwent PCI and who were treated with either ticagrelor or prasugrel.

The outcomes reported in each study and the corresponding follow-up time periods are listed in Table 1.

The following endpoints were assessed in this analysis:

- Mortality

- Myocardial infarction (MI)

- Major adverse cardiac events (MACEs) consisting of mortality, MI, and revascularization

- Stroke

- Total bleeding events including all bleeding events which were reported

- Thrombolysis in Myocardial Infarction (TIMI) [11] defined minor bleeding

- TIMI defined major bleeding [11]

- Minor bleeding defined according to the Bleeding Academic Research Consortium (BARC 1 and 2) [12]

- Major bleeding defined according to the Bleeding Academic Research Consortium $($ BARC $>2)$ [12]

- Minimal bleeding (any type of minimal bleeding)

\section{Data Extraction and Quality Assessment}

Relevant data including the number of participants with T2DM, the total number of T2DM participants assigned to the ticagrelor group, the total number of T2DM participants assigned to the prasugrel group, the baseline features of the participants, the total number of events associated with mortality, MI, MACEs, stroke, and bleeding outcomes were carefully extracted by four reviewers.

Data were cross-checked by all the reviewers. Any disagreements which followed were resolved by discussion.

The methodological quality of the trials was assessed with reference to the recommendations of the Cochrane Collaboration [13].

\section{Statistical Analysis}

Statistical analysis was carried out by the Revman software (version 5.3). Odds ratios (OR) and 95\% confidence intervals (CI) were used to represent the data during subgroup analysis.

Heterogeneity was assessed by the $Q$ statistic test. A result reporting a $P$ value less or equal to 0.05 was considered statistically significant whereas any $P$ value greater than 0.05 was considered statistically insignificant.

Heterogeneity was also assessed by the $I^{2}$ statistic test. Heterogeneity was considered to be high if the $I^{2}$ value was high. A low heterogeneity was represented by a lower $I^{2}$ value.

A fixed statistical model was used if $I^{2}$ was less than $50 \%$ whereas a random statistical model was used if $I^{2}$ was greater than $50 \%$.

Sensitivity analysis was carried out by an exclusion method. Each study was excluded one by one and a new analysis was carried out each time to observe for any significant change in the main results.

Publication bias was visually assessed by observing funnel plots.

\section{Compliance with Ethical Guidelines}

Ethical approval was not required for this study since it did not involve experiments with animals or humans performed by any of the authors. 
Table 1 Types of participants, outcomes reported, and follow-up time periods

\begin{tabular}{|c|c|c|c|}
\hline Studies & $\begin{array}{l}\text { Types of PCI } \\
\text { participants }\end{array}$ & Outcomes reported & $\begin{array}{l}\text { Follow-up } \\
\text { time period }\end{array}$ \\
\hline $\begin{array}{l}\text { Alexopoulos } \\
2012[15]\end{array}$ & $\begin{array}{l}\text { T2DM patients with } \\
\text { STEMI }\end{array}$ & Mortality, minor or minimal bleeding event & 5 days \\
\hline $\begin{array}{l}\text { Alexopoulos } \\
2013[16]\end{array}$ & $\begin{array}{l}\text { T2DM patients with } \\
\text { ACS }\end{array}$ & Major bleeding, MACEs, BARC 1 bleeding & 15 days \\
\hline $\begin{array}{l}\text { Alexopoulos } \\
\text { 2012B [17] }\end{array}$ & $\begin{array}{l}\text { T2DM patients with } \\
\text { non-STEMI }\end{array}$ & Major bleeding, MACEs, BARC 1 and 2 bleeding & 15 days \\
\hline $\begin{array}{l}\text { Bonello } 2015 \\
\quad[18]\end{array}$ & $\begin{array}{l}\text { T2DM patients with } \\
\text { ACS }\end{array}$ & $\begin{array}{l}\text { Cardiovascular death, MACEs, BARC }>2 \text { bleeding events, } \\
\text { stroke }\end{array}$ & 30 days \\
\hline $\begin{array}{l}\text { Conrotto } 2018 \\
\quad[19]\end{array}$ & $\begin{array}{l}\text { T2DM patients with } \\
\text { ACS }\end{array}$ & Mortality, MI, MACEs, stroke, BARC 2-5 bleeding & 19 months \\
\hline $\begin{array}{l}\text { Dimitroulis } \\
2018[20]\end{array}$ & $\begin{array}{l}\text { T2DM patients with } \\
\text { STEMI }\end{array}$ & $\begin{array}{l}\text { MACCEs, all-cause mortality, cardiovascular death, MI, stroke, } \\
\text { TIMI major and TIMI minor bleeding }\end{array}$ & 12 months \\
\hline $\begin{array}{l}\text { Franchi } 2016 \\
\qquad[21]\end{array}$ & $\begin{array}{l}\text { T2DM patients with } \\
\text { CAD }\end{array}$ & BARC 1-5 bleeding, dyspnea & 7 days \\
\hline $\begin{array}{l}\text { Hochholzer } \\
2017[22]\end{array}$ & $\begin{array}{l}\text { T2DM patients with } \\
\text { CAD }\end{array}$ & Death, MI, TIMI major and minor bleeding, BARC 3-5 & 30 days \\
\hline $\begin{array}{l}\text { Laine } 2014 \\
\quad[23]\end{array}$ & $\begin{array}{l}\text { T2DM patients with } \\
\text { ACS }\end{array}$ & Death, MACEs & In-hospital \\
\hline $\begin{array}{l}\text { Motovska } \\
2016[24]\end{array}$ & $\begin{array}{l}\text { T2DM patients with } \\
\text { AMI }\end{array}$ & $\begin{array}{l}\text { TIMI major, TIMI minor, TIMI minimal bleeding, BARC 1-5, } \\
\text { MACEs, MI, stroke, death }\end{array}$ & 30 days \\
\hline $\begin{array}{l}\text { Parodi } 2013 \\
\quad[25]\end{array}$ & $\begin{array}{l}\text { T2DM patients with } \\
\text { STEMI }\end{array}$ & $\begin{array}{l}\text { Death, MI, stroke, TIMI major, minor, minimal bleeding, } \\
\text { dyspnea }\end{array}$ & In-hospital \\
\hline Perl $2014[26]$ & $\begin{array}{l}\text { T2DM patients with } \\
\text { AMI }\end{array}$ & Bleeding events & 30 days \\
\hline $\begin{array}{l}\text { Song } 2017 \\
\quad[27]\end{array}$ & $\begin{array}{l}\text { T2DM patients with } \\
\text { ACS }\end{array}$ & Mortality & 365 days \\
\hline
\end{tabular}

PCI percutaneous coronary intervention, T2DM type 2 diabetes mellitus, STEMI ST segment elevated myocardial infarction, $A C S$ acute coronary syndrome, $C A D$ coronary artery disease, $A M I$ acute myocardial infarction, $M A C E s$ major adverse cardiac events, $M A C C E s$ major adverse cardiovascular and cerebrovascular events, $B A R C$ bleeding defined according to the Bleeding Academic Research Consortium, TIMI Thrombolysis in Myocardial Infarction, $M I$ myocardial infarction

\section{RESULTS}

\section{Search Outcomes}

Searched outcomes (Preferred Reporting Items for Systematic reviews and Meta-Analyses: PRISMA guideline) [14] resulted in a total of 745 articles. Following a careful assessment of the titles and abstracts, 698 articles were eliminated. Forty-seven (47) full-text articles were assessed for eligibility. Further eliminations were carried out for the following reasons: meta-analyses (3), letters of correspondence (3), reported only platelet outcomes (11), reported 


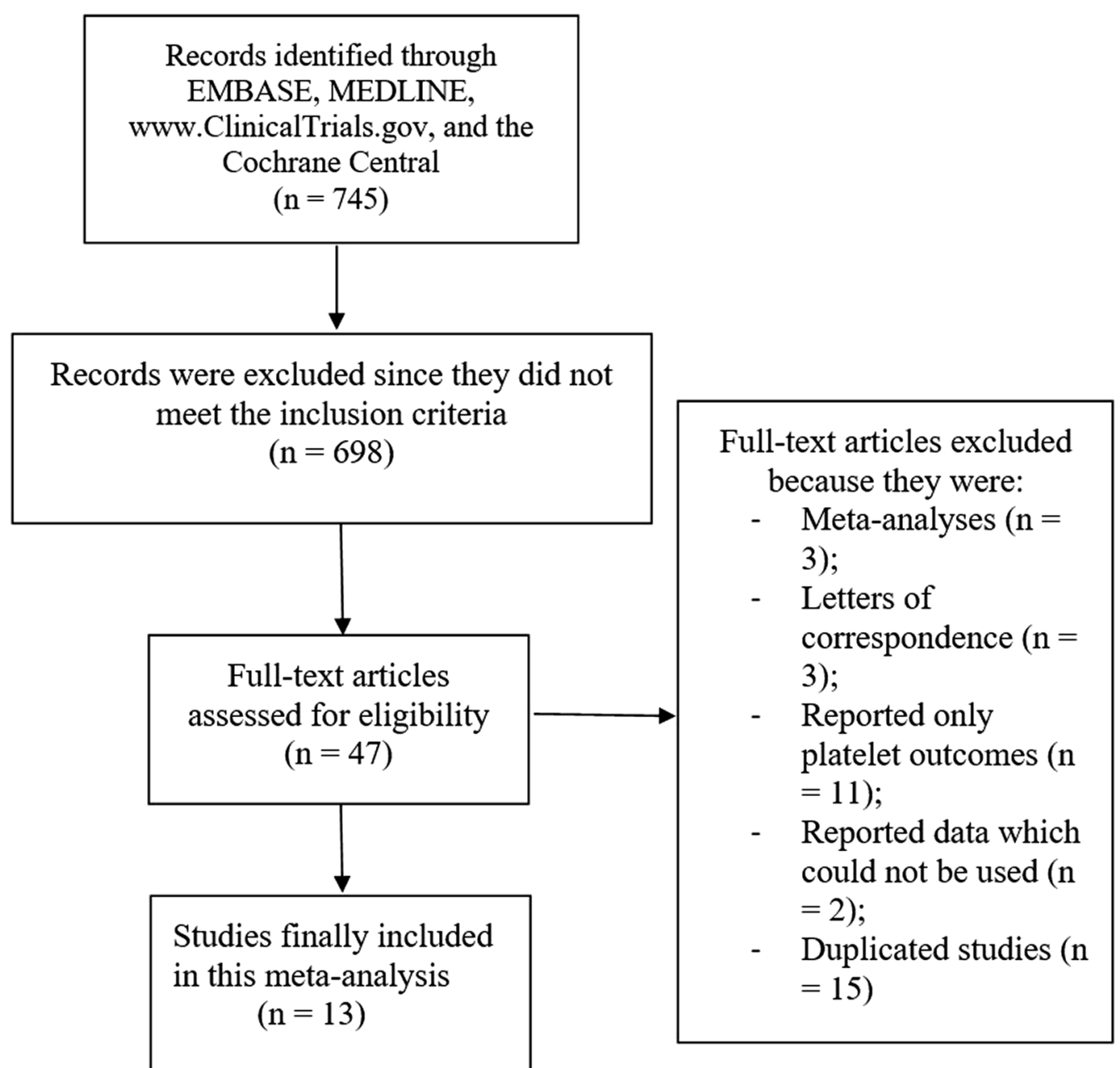

Fig. 1 Flow diagram representing the flow of study selection

data which could not be used in this analysis (2), duplicated studies (15). Finally, 13 articles [15-27] were selected for this analysis as shown in Fig. 1.

\section{Main and Baseline Features of the Studies and Participants}

A total of 2004 participants with T2DM were included in this analysis; of these, 996 T2DM participants were assigned to ticagrelor whereas 1008 T2DM participants were assigned to prasugrel. The enrollment period was between years 2012 and 2016 as shown in Table 2 . Table 2 lists the number of T2DM participants extracted from each study.
Table 3 lists the baseline features of the T2DM participants. The mean age of the patients varied from 55.8 to 71.8 years. The majority of participants were male. The percentages of participants with hypertension, dyslipidemia, and a smoking history are reported in Table 3.

\section{Post-Interventional Clinical Outcomes and Bleeding Events Observed with Ticagrelor Versus Prasugrel in Patients with Type 2 Diabetes Mellitus}

Following PCI, when the adverse clinical outcomes were assessed in T2DM patients who were assigned to ticagrelor versus prasugrel, 
Table 2 General features of the studies

\begin{tabular}{lllcc}
\hline Studies & Type of study & $\begin{array}{l}\text { Participants' } \\
\text { enrollment } \\
\text { period }\end{array}$ & $\begin{array}{l}\text { No. of T2DM } \\
\text { participants assigned } \\
\text { to ticagrelor group }(\boldsymbol{n})\end{array}$ & $\begin{array}{l}\text { No. of T2DM } \\
\text { participants assigned } \\
\text { to prasugrel group }(\boldsymbol{n})\end{array}$ \\
\hline Alexopoulos 2012 & NRT & - & 3 & 2 \\
Alexopoulos 2013 & NRT & 2012 & 15 & 15 \\
Alexopoulos 2012B & RT & 2012 & 6 & 4 \\
Bonello 2015 & RT & 2014 & 31 & 44 \\
Conrotto 2018 & NRT & $2012-2016$ & 386 & 386 \\
Dimitroulis 2018 & NRT & $2012-2015$ & 30 & 32 \\
Franchi 2016 & RT & $2013-2015$ & 24 & 26 \\
Hochholzer 2017 & RT & 2016 & 10 & 9 \\
Laine 2014 & RT & $2012-2013$ & 50 & 127 \\
Motovska 2016 & RT & $2013-2016$ & 124 & 6 \\
Parodi 2013 & RT & 2012 & 3 & 17 \\
Perl 2014 & NRT & - & 19 & 290 \\
Song 2017 & NRT & $2013-2014$ & 295 & 1008 \\
Total no. of participants $(n)$ & & & 996 & \\
\hline
\end{tabular}

$N R T$ non-randomized trial, $R T$ randomized trial, T2DM type 2 diabetes mellitus

mortality (OR 1.00, 95\% CI 0.57-1.76; $P=0.99$, $I^{2}=19 \%$ ), MI (OR 0.86, 95\% CI 0.42-1.75; $P=0.67, I^{2}=0 \%$ ), MACEs (OR 0.73, 95\% CI $\left.0.42-1.27 ; P=0.27, I^{2}=0 \%\right)$, and stroke (OR $0.72,95 \%$ CI $0.20-2.59 ; P=0.61, I^{2}=0 \%$ ) were not significantly different between the two different groups of antiplatelet agents as shown in Fig. 2.

The post-interventional bleeding events were also assessed following ticagrelor or prasugrel use in these patients with T2DM. Total bleeding events (OR 0.87, 95\% CI 0.55-1.40; $P=0.58$, $I^{2}=6 \%$ ), TIMI defined minor bleeding (OR 2.39, 95\% CI 0.58-9.91; $P=0.23, I^{2}=0 \%$ ), TIMI defined major bleeding (OR 1.42, 95\% CI $\left.0.27-7.45 ; \quad P=0.68, \quad I^{2}=0 \%\right), \quad$ BARC major bleeding (OR 0.55, 95\% CI 0.22-1.36; $P=0.20$, $\left.I^{2}=0 \%\right)$, BARC minor bleeding (OR 1.44, 95\% CI $\left.0.52-3.99 ; \quad P=0.48, \quad I^{2}=0 \%\right)$, and total minimal bleeding (OR 3.12, 95\% CI 0.55-17.59; $\left.P=0.20, I^{2}=0 \%\right)$ were not significantly different as shown in Fig. 3.
The results are summarized in Table 4 .

\section{Sensitivity Analysis and Publication Bias}

When each study was excluded one by one and a new analysis was carried out, consistent results were obtained throughout. Publication bias was visually assessed through funnel plots. Based on this assessment, a low evidence of publication bias was observed across all the studies that assessed the post-interventional clinical outcomes and bleeding events observed with ticagrelor versus prasugrel in these patients with T2DM as shown in Figs. 4 and 5.

\section{DISCUSSION}

The post-interventional clinical outcomes and bleeding events observed with ticagrelor versus prasugrel were compared in patients with T2DM. Findings of this analysis showed no 
Table 3 Baseline features of the participants

\begin{tabular}{llllll}
\hline Studies & $\begin{array}{l}\text { Age (years) } \\
\text { Tica/Prasu }\end{array}$ & $\begin{array}{l}\text { Male (\%) } \\
\text { Tica/Prasu }\end{array}$ & $\begin{array}{l}\text { HBP (\%) } \\
\text { Tica/Prasu }\end{array}$ & $\begin{array}{l}\text { DSL (\%) } \\
\text { Tica/Prasu }\end{array}$ & $\begin{array}{l}\text { CS (\%) } \\
\text { Tica/Prasu }\end{array}$ \\
\hline Alexopoulos 2012 & $58.0 / 61.0$ & $86.0 / 74.0$ & $43.0 / 44.0$ & $46.0 / 59.0$ & $64.0 / 48.0$ \\
Alexopoulos 2013 & $60.9 / 65.4$ & $93.3 / 93.3$ & $73.3 / 66.7$ & $46.7 / 53.3$ & $33.3 / 40.0$ \\
Alexopoulos 2012B & $55.8 / 57.4$ & $92.9 / 82.1$ & $57.1 / 53.6$ & $67.9 / 42.9$ & $64.3 / 42.9$ \\
Bonello 2015 & $61.5 / 60.0$ & $69.8 / 79.8$ & $52.8 / 57.9$ & $53.3 / 45.3$ & $48.0 / 36.8$ \\
Conrotto 2018 & $62.6 / 62.9$ & $79.5 / 80.8$ & $67.6 / 68.4$ & $63.0 / 65.3$ & $43.8 / 40.2$ \\
Dimitroulis 2018 & $63.0 / 57.0$ & $76.0 / 81.0$ & $65.0 / 53.0$ & $24.0 / 22.0$ & $49.0 / 58.0$ \\
Franchi 2016 & $59.0 / 59.0$ & $72.0 / 72.0$ & $93.0 / 93.0$ & $87.0 / 87.0$ & $24.0 / 24.0$ \\
Hochholzer 2017 & $69.0 / 70.0$ & $78.0 / 82.0$ & $80.0 / 84.0$ & $96.0 / 84.0$ & - \\
Laine 2014 & $64.8 / 62.8$ & $66.0 / 86.0$ & $80.0 / 70.0$ & $56.0 / 62.0$ & $28.0 / 28.0$ \\
Motovska 2016 & $61.8 / 61.8$ & $73.7 / 77.1$ & $51.2 / 51.4$ & $35.4 / 33.4$ & $65.8 / 64.0$ \\
Parodi 2013 & $67.0 / 67.0$ & $76.0 / 80.0$ & $72.0 / 60.0$ & $40.0 / 20.0$ & $36.0 / 36.0$ \\
Perl 2014 & $63.2 / 57.5$ & $80.8 / 79.0$ & $63.5 / 43.5$ & $63.5 / 59.7$ & $34.6 / 51.6$ \\
Song 2017 & $71.8 / 71.7$ & $64.6 / 65.3$ & $86.6 / 87.0$ & $82.1 / 81.7$ & $16.5 / 16.5$ \\
\hline
\end{tabular}

$H B P$ hypertension, $D S L$ dyslipidemia, $C S$ current smoker, Tica ticagrelor group, Prasu prasugrel group

significant difference in mortality, MI, MACEs, stroke, total bleeding events, TIMI defined major and minor bleedings, BARC major and minor bleedings as well as no significant difference in minimal bleeding events.

Recently, the Prasugrel versus Ticagrelor in Patients with Acute Myocardial Infarction Treated with Primary Percutaneous Coronary Intervention (PRAGUE-18) Trial which compared these two newer potent antiplatelets with clopidogrel showed that the latter was inferior in terms of efficacy [28]. However, bleeding risk was increased with ticagrelor and prasugrel in comparison with clopidogrel. In the PRAGUE18 trial, ticagrelor and prasugrel were compared with clopidogrel. But in this analysis, ticagrelor was compared with prasugrel and the results showed no significant difference in patients with T2DM.

A subgroup analysis of a randomized, openlabel, crossover study conducted in different US centers and which included 21 patients with T2DM showed that even with stable coronary artery disease, ticagrelor could achieve a faster onset and a greater magnitude of platelet inhibition in comparison to clopidogrel [29], which would be an advantage for patients with T2DM who were more prone to platelet hyperactivity [9]. It should be noted that hyperactive platelets in patients with T2DM were due to the increased expression of the platelet surface adhesion receptors and molecules, and due to enhanced production of thromboxane as well as thrombin, resulting in easy and rigorous aggregation of platelets. Increased prostaglandin synthetase activity, increased arachiodonic acid metabolism, and decreased antioxidant levels have also been linked to the mechanisms involved in hyperactive platelets in patients with T2DM [30]. Other explanations for platelet dysfunctions were related to the production of immature, larger platelets by the bone marrow, and activation of platelets due to repeated vascular damage in these patients with T2DM [31].

However, the controversy associated with these new potential antiplatelet agents does not appear to be reaching an end soon. Data from the large, multicenter, international Registry of New Antiplatelets in patients with Myocardial Infarction (RENAMI) having a longer follow-up 


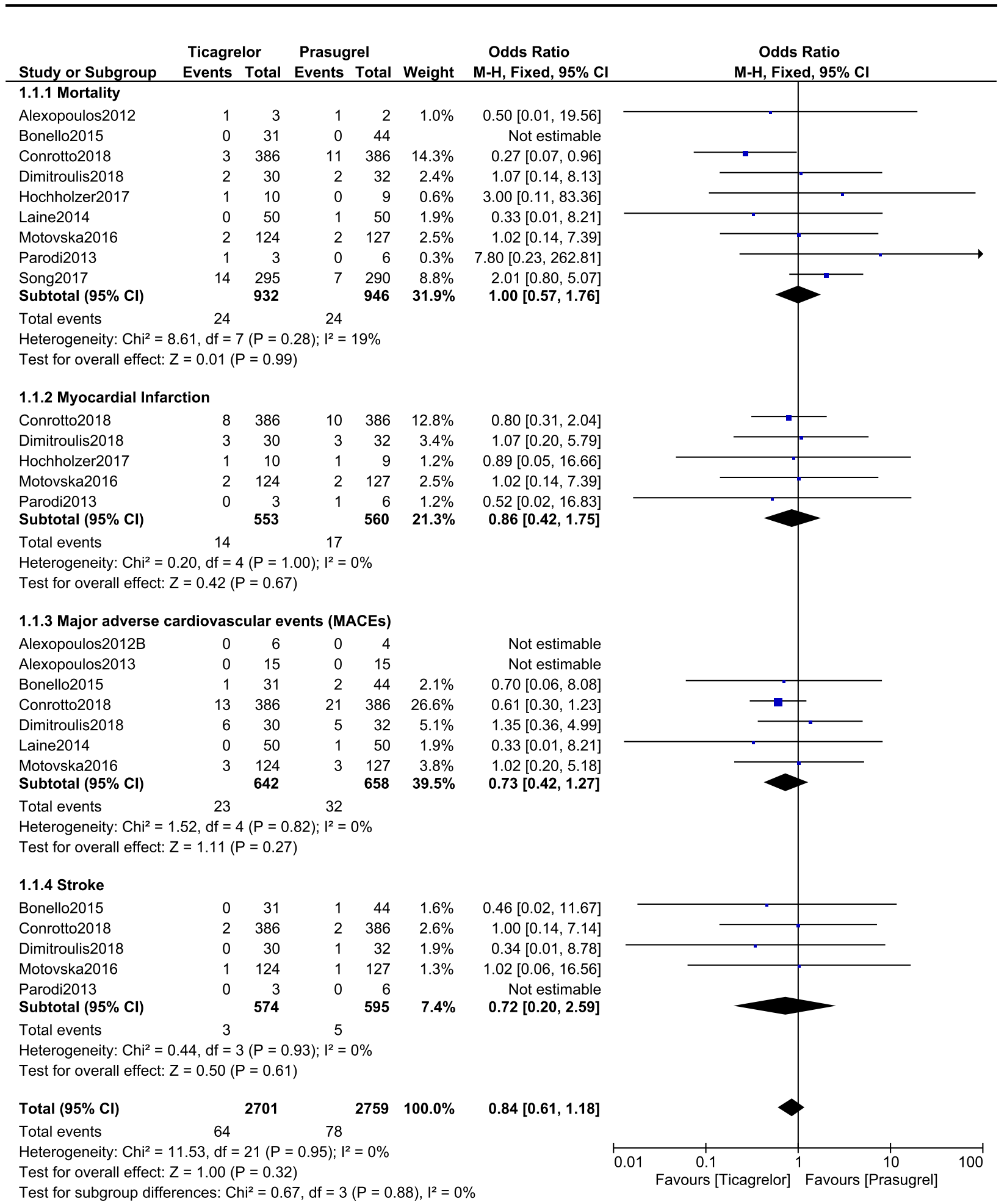

Fig. 2 Post-interventional clinical outcomes observed with ticagrelor versus prasugrel in patients with type 2 diabetes mellitus 


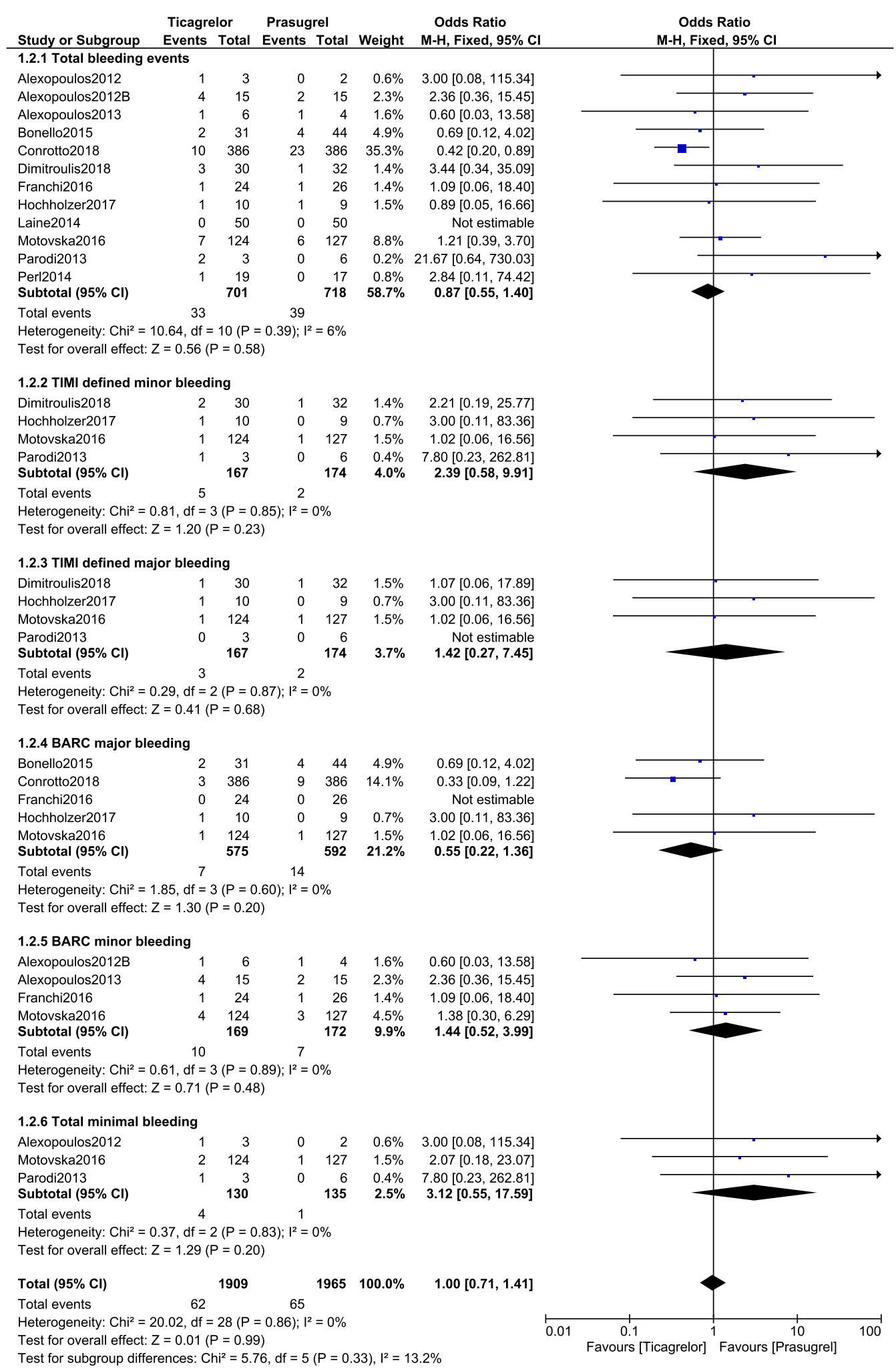

Fig. 3 Post-interventional bleeding events observed with ticagrelor versus prasugrel in patients with type 2 diabetes mellitus 
Table 4 Summarized results of the analysis comparing the outcomes observed with ticagrelor versus prasugrel in patients with type 2 diabetes mellitus

\begin{tabular}{lclll}
\hline Endpoints assessed & Total no. of studies $(\mathbf{n})$ & OR with 95\% CI & $\boldsymbol{P}$ value & $\boldsymbol{I}^{\mathbf{2}}$ value (\%) \\
\hline Mortality & 9 & $1.00(0.57-1.76)$ & 0.99 & 19 \\
Myocardial infarction & 5 & $0.86(0.42-1.75)$ & 0.67 & 0 \\
MACEs & 7 & $0.73(0.42-1.27)$ & 0.27 & 0 \\
Stroke & 5 & $0.72(0.20-2.59)$ & 0.61 & 0 \\
Total bleeding events & 12 & $0.87(0.55-1.40)$ & 0.58 & 6 \\
TIMI minor bleeding & 4 & $2.39(0.58-9.91)$ & 0.23 & 0 \\
TIMI major bleeding & 4 & $1.42(0.27-7.45)$ & 0.68 & 0 \\
BARC bleeding (minor) & 4 & $1.44(0.52-3.99)$ & 0.48 & 0 \\
BARC bleeding (major) & 5 & $0.55(0.22-1.36)$ & 0.20 & 0 \\
Minimal bleeding & 3 & $3.12(0.55-17.59)$ & 0.20 & 0 \\
\hline
\end{tabular}

OR odds ratios, $C I$ confidence intervals, TIMI Thrombolysis in Myocardial Infarction, BARC bleeding defined by the Bleeding Academic Research Consortium, MACEs major adverse cardiac events

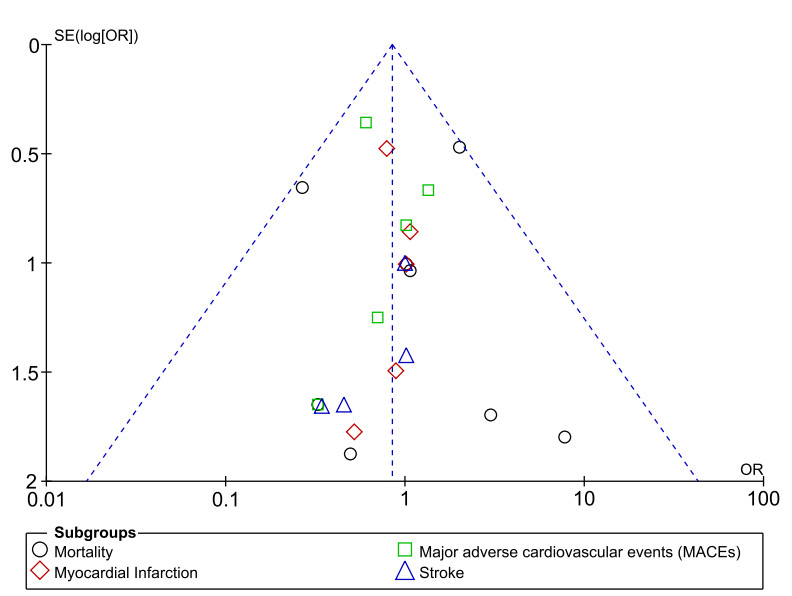

Fig. 4 Funnel plot representing publication bias

of the participants (19 months) showed major adverse cardiac events to be similar between ticagrelor and prasugrel in patients with T2DM [19]. However, ticagrelor was associated with a lower risk of both death and BARC bleeding [19]. Moreover, a review of literature based on clinical trials showed that ticagrelor and prasugrel significantly reduced ischemic events in comparison to clopidogrel, and ticagrelor and clopidogrel showed comparable bleeding risks [32]. However, prasugrel was associated with a

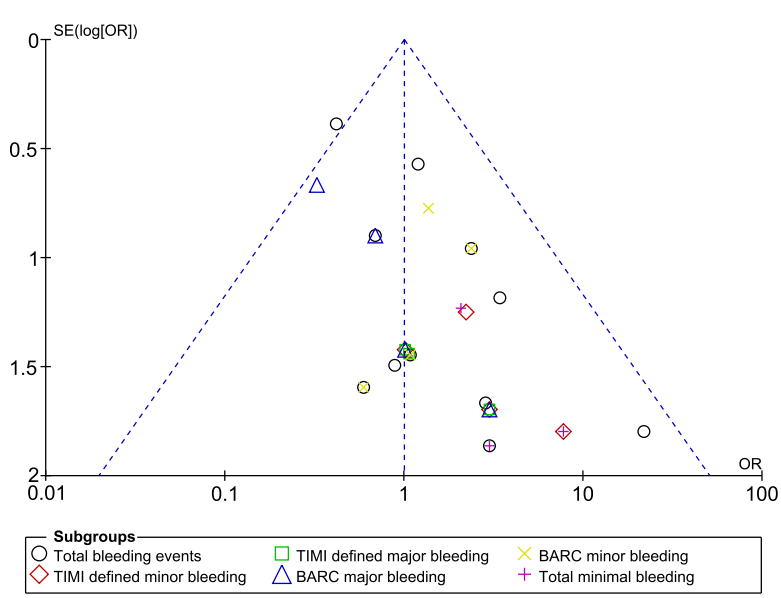

Fig. 5 Funnel plot representing publication bias

significantly higher major bleeding risk. This effect was mainly observed in female and older patients [33]. Nevertheless, this current analysis, while directly comparing ticagrelor versus prasugrel in patients with T2DM, did not show any significant difference in bleeding events.

\section{Limitations}

This analysis has certain limitations. First of all, because of the small total number of 
participants, the results might have been affected. Secondly, the dosage of ticagrelor and prasugrel might have had an influence on the outcomes. Additionally, the use of other antiplatelet and other cardiac medications was ignored in this analysis. Also, a few studies reported a crossover from prasugrel to ticagrelor and vice versa. The follow-up time period was also not equivalent in the studies. Another limitation could be the fact that this analysis included data which were extracted from both randomized and non-randomized trials.

\section{CONCLUSIONS}

Ticagrelor and prasugrel were not associated with significantly different adverse clinical outcomes and bleeding events in these patients with T2DM. Therefore, both antiplatelet agents might safely be used in patients with T2DM following coronary intervention. However, this head-to-head comparison still remains a major challenge which should be resolved in larger clinical trials.

\section{ACKNOWLEDGEMENTS}

Funding. No funding or sponsorship was received for this study or publication of this article.

Authorship. All named authors meet the International Committee of Medical Journal Editors (ICMJE) criteria for authorship for this article, take responsibility for the integrity of the work as a whole, and have given their approval for this version to be published.

Authorship Contributions. Hua Yang, Bing Tang, Chen Hong $\mathrm{Xu}$, and Anis Ahmed were responsible for the conception and design, acquisition of data, analysis and interpretation of data, drafting the initial manuscript and revising it critically for important intellectual content. Hua Yang wrote the final draft of the manuscript. Hua Yang, Bing Tang, Chen Hong
$\mathrm{Xu}$, and Anis Ahmed approved the final manuscript as it is.

Disclosures. The authors Dr Hua Yang, Dr Bing Tang, Dr Chen Hong $\mathrm{Xu}$, and Dr Anis Ahmed declare that they have no competing interests.

Compliance with Ethical Guidelines. This meta-analysis is based on previously conducted studies and does not contain any studies with human participants or animals performed by any of the authors.

Data Availability. All data generated or analyzed during this study are included in this published article.

Open Access. This article is distributed under the terms of the Creative Commons Attribution-NonCommercial 4.0 International License (http://creativecommons.org/licenses/ by-nc/4.0/), which permits any noncommercial use, distribution, and reproduction in any medium, provided you give appropriate credit to the original author(s) and the source, provide a link to the Creative Commons license, and indicate if changes were made.

\section{REFERENCES}

1. Ko SQ, Valsdottir LR, Strom JB, et al. Meta-analysis of bleeding risk prediction scores in patients after percutaneous coronary intervention on dual antiplatelet therapy. Am J Cardiol. 2018;9149(18)31724-7.

2. $\mathrm{Xu} \mathrm{Z}, \mathrm{Gu}$ J, Gao M, et al. Study on antiplatelet effect of a new thiophenopyridine platelets $\mathrm{P}_{2} \mathrm{Y}_{12}$ receptor antagonist DV-127. Thromb Res. 2018;170:192-9.

3. Wallentin L, Becker RC, Budaj A, et al. Ticagrelor versus clopidogrel in patients with acute coronary syndromes. N Engl J Med. 2009;361:1045-57.

4. Wiviott SD, Braunwald E, McCabe CH, et al. Prasugrel versus clopidogrel in patients with acute coronary syndromes. N Engl J Med. 2007;357:2001-15. 
5. Gurbel PA, Bliden KP, Butler K, et al. Randomized double-blind assessment of the ONSET and OFFSET of the antiplatelet effects of ticagrelor versus clopidogrel in patients with stable coronary artery disease: the ONSET/OFFSET study. Circulation. 2009;120(25):2577-85.

6. Steg PG, James SK, Atar D, et al. ESC guidelines for the management of acute myocardial infarction in patients presenting with ST-segment elevation. Eur Heart J. 2012;33(20):2569-619.

7. Bundhun PK, Shi JX, Huang F. Head to head comparison of prasugrel versus ticagrelor in patients with acute coronary syndrome: a systematic review and meta-analysis of randomized trials. BMC Pharmacol Toxicol. 2017;18(1):80.

8. Sakurai R, Burazor I, Bonneau HN, Kaneda H. Headto-head comparison of prasugrel versus ticagrelor in patients undergoing percutaneous coronary intervention: a meta-analysis of randomized controlled trials. J Interv Cardiol. 2017;30(5):457-64.

9. $\mathrm{Hu} \mathrm{L}$, Chang L, Zhang Y, et al. Platelets express activated $\mathrm{P}_{2} \mathrm{Y}_{12}$ receptor in patients with diabetes mellitus. Circulation. 2017;136(9):817-33.

10. Tantry US, Navarese EP, Bliden KP, Gurbel PA. Acetylsalicylic acid and clopidogrel hyporesponsiveness following acute coronary syndromes. Kardiol Pol. 2018;76(9):1312-9.

11. TIMI Study Group. The Thrombolysis in Myocardial Infarction (TIMI) trial. Phase I findings. N Engl J Med. 1985;312(14):932-6.

12. Mehran R, Rao SV, Bhatt DL, et al. Standardized bleeding definitions for cardiovascular clinical trials: a consensus report from the Bleeding Academic Research Consortium. Circulation. 2011;123(23):2736-47.

13. Higgins JP, Altman DG. Assessing risk of bias in included studies. In Higgins JPT, Green S, editors. Cochrane handbook for systematic reviews of interventions. Chichester: Wiley; 2008. p. 187-241.

14. Liberati A, Altman DG, Tetzlaff J, et al. The PRISMA statement for reporting systematic reviews and meta-analyses of studies that evaluate healthcare interventions: explanation and elaboration. BMJ. 2009;339:b2700.

15. Alexopoulos D, Xanthopoulou I, Gkizas V, et al. Randomized assessment of ticagrelor versus prasugrel antiplatelet effects in patients with ST-segment-elevation myocardial infarction. Circ Cardiovasc Interv. 2012;5(6):797-804.

16. Alexopoulos D, Xanthopoulou I, Mavronasiou E, et al. Randomized assessment of ticagrelor versus prasugrel antiplatelet effects in patients with diabetes. Diabetes Care. 2013;36(8):2211-6.

17. Alexopoulos D, Moulias A, Koutsogiannis N, et al. Differential effect of ticagrelor versus prasugrel on coronary blood flow velocity in patients with nonST-elevation acute coronary syndrome undergoing percutaneous coronary intervention: an exploratory study. Circ Cardiovasc Interv. 2013;6(3):277-83.

18. Bonello L, Laine M, Cluzel M, et al. Comparison of ticagrelor versus prasugrel to prevent periprocedural myonecrosis in acute coronary syndromes. Am J Cardiol. 2015;116(3):339-43.

19. Conrotto F, Bertaina M, Raposeiras-Roubin S, et al. Prasugrel or ticagrelor in patients with acute coronary syndrome and diabetes: a propensity matched substudy of RENAMI. Eur Heart J Acute Cardiovasc Care. 2018;1:2048872618802783.

20. Dimitroulis D, Golabkesh M, Naguib D, et al. Safety and efficacy in prasugrel- versus ticagrelor-treated patients with ST-elevation myocardial infarction. J Cardiovasc Pharmacol. 2018;72(4):186-90.

21. Franchi F, Rollini F, Aggarwal N, et al. Pharmacodynamic comparison of prasugrel versus ticagrelor in patients with type 2 diabetes mellitus and coronary artery disease: the OPTIMUS (optimizing antiplatelet therapy in diabetes mellitus)-4 study. Circulation. 2016;134(11):780-92.

22. Hochholzer W, Kleiner P, Younas I, et al. Randomized comparison of oral $\mathrm{P}_{2} \mathrm{Y}_{12}$-receptor inhibitor loading strategies for transitioning from cangrelor: the ExcelsiorLOAD2 Trial. JACC Cardiovasc Interv. 2017;10(2):121-9.

23. Laine $M$, Frère $C$, Toesca $R$, et al. Ticagrelor versus prasugrel in diabetic patients with an acute coronary syndrome. A pharmacodynamic randomised study. Thromb Haemost. 2014;111(2):273-8.

24. Motovska Z, Hlinomaz O, Miklik R, et al. Prasugrel versus ticagrelor in patients with acute myocardial infarction treated with primary percutaneous coronary intervention: multicenter randomized PRAGUE-18 study. Circulation. 2016;134(21):1603-12.

25. Parodi G, Valenti R, Bellandi B, et al. Comparison of prasugrel and ticagrelor loading doses in ST-segment elevation myocardial infarction patients: RAPID (rapid activity of platelet inhibitor drugs) primary PCI study. J Am Coll Cardiol. 2013;61(15):1601-6.

26. Perl L, Zemer-Wassercug N, Rechavia E, et al. Comparison of platelet inhibition by prasugrel versus ticagrelor over time in patients with acute myocardial infarction. J Thromb Thrombolysis. 2015;39(1):1-7. 
27. Song C, Sukul D, Seth M, et al. Ninety-day readmission and long-term mortality in medicare patients ( $\geq 65$ years) treated with ticagrelor versus prasugrel after percutaneous coronary intervention (from the Blue Cross Blueshield of Michigan Cardiovascular Consortium). Am J Cardiol. 2017;120(11):1926-32.

28. Amsterdam EA, Wenger NK, Brindis RG, et al. 2014 AHA/ACC guideline for the management of patients with non-ST-elevation acute coronary syndromes: executive summary: a report of the American College of Cardiology/American Heart Association Task Force on Practice Guidelines. Circulation 201;130(25):2354-94.

29. Clavijo LC, Maya J, Carlson G, et al. Platelet inhibition with ticagrelor versus clopidogrel in Hispanic patients with stable coronary artery disease with or without diabetes mellitus. Cardiovasc Revasc Med. 2015;16(8):450-4.
30. Gaiz A, Mosawy S, Colson N, Singh I. Thrombotic and cardiovascular risks in type two diabetes; Role of platelet hyperactivity. Biomed Pharmacother. 2017;94:679-86.

31. Vinik AI, Erbas T, Park TS, Nolan R, Pittenger GL. Platelet dysfunction in type 2 diabetes. Diabetes Care. 2001;24(8):1476-85.

32. Roffman DS. Developments in Oral antiplatelet agents for the treatment of acute coronary syndromes: clopidogrel, prasugrel, and ticagrelor. J Pharm Pract. 2016;29(3):239-49.

33. D'Ascenzo F, Grosso A, Abu-Assi E, et al. Incidence and predictors of bleeding in ACS patients treated with PCI and prasugrel or ticagrelor: an analysis from the RENAMI registry. Int $\mathrm{J}$ Cardiol. 2018;273:29-33. 